elSSN: $2444-7986$

DOI: http://dx.doi.org/10.14201/orl201671.13875

Carta al Director

\title{
COLABORACIÓN BIBLIOTECAS DE LA USAL Y SOCIEDAD OTORRINOLARINGOLÓGICA DE CASTILLA Y LEÓN, CANTABRIA Y LA RIOJA
}

\section{Collaboration Libraries USAL and Otolaryngological Society of Cas- tilla y León, Cantabria and La Rioja}

\author{
José Antonio MERLO-VEGA; Tránsito FERRERAS-FERNÁNDEZ* \\ Universidad de Salamanca. Servicio de Bibliotecas. \\ ${ }^{*}$ Correspondencia: transiff@usal.es
}

Fecha de recepción: 14 de febrero de 2016

Fecha de aceptación: 15 de febrero de 2016

Fecha de Publicación: 21 de febrero de 2016

Conflicto de intereses: Los autores declaran no tener conflictos de intereses

Imágenes: Los autores declaran haber obtenido las imágenes con el permiso de los pacientes

Política de derechos y autoarchivo: se permite el autoarchivo de la versión post-print (SHERPA/RoMEO)

Licencia CC BY-NC-ND. Licencia Creative Commons Atribución-NoComercial-SinDerivar 4.0 Internacional

(C) Universidad de Salamanca. Su comercialización está sujeta al permiso del editor

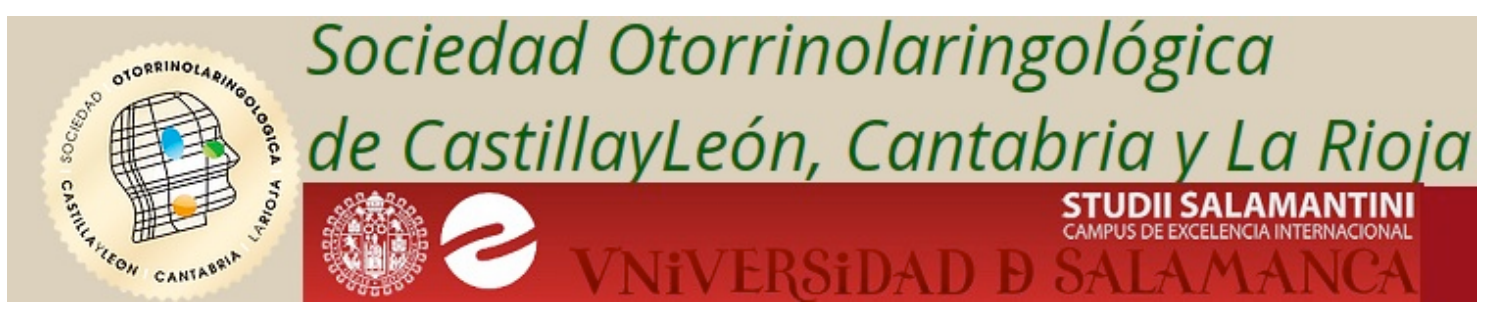

Señor Director:

La Universidad de Salamanca ha firmado un convenio con la Sociedad Otorrinolaringológica de Castilla y León, Cantabria y La Rioja $^{1,2}$ (Sociedad ORL CLCR). El convenio fue aprobado por la Comisión Permanente de la Universidad de Salamanca el 10 de diciembre

\footnotetext{
${ }^{1}$ http://www.sociedadorl.com

2 Documento:

http://revistas.usal.es/index.php/2444-

7986/manager/files/DOCUMENTACION/CONVENIOUSA L-SORLCLCR_FIRMADO_FEBRERO2016.pdf
}

(C) Ediciones Universidad de Salamanca / CC BY-NC-ND [65] de 2015 y firmado por ambas instituciones el 18 de enero de 2016 [1].

Se trata de un Convenio Básico de Colaboración que ha sido promovido por la Universidad de Salamanca y la Sociedad ORL CLCR ya que ambas organizaciones se encuentran unidas por objetivos comunes en las áreas de la documentación, la edición, la formación y la investigación.

De igual modo, ambas instituciones promueven el intercambio de conocimiento y fomentan la investigación de acuerdo a las tareas que les son propias. Una de las funciones de la Universidad de Salamanca es el asesora- 
miento científico, técnico y formativo, para contribuir a la mejora de la calidad de vida y al desarrollo de la comunidad en todos sus ámbitos, entre los que se encuentra la difusión y publicación en acceso abierto de contenidos científicos en el área de la biomedicina. Por su parte, la Sociedad ORL CLCR agrupa a médicos especialistas en Otorrinolaringología y disciplinas afines; y desde 2010 publica Revista ORL como revista científica y órgano de expresión de la Sociedad, cuyo acceso a los contenidos siempre ha sido abierto y libre de cargos para autores y lectores.

El presente Convenio tiene como objeto regular las actividades formativas y de asesoramiento de la Universidad de Salamanca a la Sociedad ORL CLCR. La colaboración entre ambas instituciones comenzó ya en 2014 con el autoarchivo y difusión de la Revista ORL de la Sociedad ORL CLCR a través de GREDOS $^{3}$, el Repositorio Institucional de la Universidad de Salamanca, colaboración que continuó en 2015 con la realización de tareas de asesoría técnica y de formación en las áreas de la documentación y de la información para los miembros de la Sociedad.

Actualmente, desde la Coordinación de Servicios Bibliotecarios y desde la Dirección de la Biblioteca de la Facultad de Medicina, se colabora por un lado en el comité editorial de Revista ORL ${ }^{4}$, que ha pasado a publicarse por Ediciones Universidad de Salamanca ${ }^{5}$, y por otro lado en la programación y organización de actividades formativas para los miembros de la Sociedad ORL CLCR.

Inicialmente en 2016, y ya en el marco de este convenio, se ha previsto la realización de una serie de cursos/taller de lectura crítica (Facultad de Medicina de la USAL) y de búsquedas bibliográficas/gestores bibliográficos (Hospital Universitario de Burgos o UBU).

Como manifiesta el Dr. José Luis Pardal Refoyo, Director de Revista ORL, el convenio deja abierta la posibilidad de mejorar mutuamente la formación en los aspectos de metodología, documentación e investigación que fue el germen de esta cooperación que surgió desde el Servicio de Bibliotecas de la Universidad de Salamanca ${ }^{6}$.

\section{REFERENCIAS}

1. Gredos. Colaboración Bibliotecas de la USAL y Sociedad Otorrinolaringológica de Castilla y León, Cantabria y La Rioja. El blog de Gredos [Internet]. [citado 14 de febrero de 2016]. Recuperado a partir de: http://diarium.usal.es/gredos/2016/02/08/c onvenio-de-colaboracion-institucionalentre-la-sociedad-otorrinolaringologica-decastilla-y-leon-cantabria-y-la-rioja-y-launiversidad-de-salamanca/

\footnotetext{
${ }^{3} \mathrm{http}: / /$ www.gredos.usal.es

${ }^{4}$ http://revistas.usal.es/index.php/2444-7986/index

${ }^{5} \mathrm{http}: / /$ www.eusal.es

${ }^{6}$ Carta interior al Consejo de Redacción y al Consejo Asesor de Revista ORL (7 de febrero de 2016) (Asunto:

CONVENIO DE COLABORACIÓN CON LA UNIVERSIDAD DE SALAMANCA) 